\title{
EN EL CORAZÓN DE LA NEGRITUD: EL ROL DE PAULETTE NARDAL EN LAS REVISTAS ANTILLANAS (1931-1951) ${ }^{1}$
}

\author{
AT THE HEART OF NEGRITUDE: PAULETTE NARDAL'S ROLE IM \\ WEST INDIAN MAGAZINES (1931-1951)
}

\author{
María José YaKsic \\ Universidad de Chile \\ Grecia 958, Nuñoa, Santiago, Chile \\ mayaksic@gmail.com
}

\begin{abstract}
RESUMeN
En las últimas dos décadas, un conjunto de investigaciones anglo y francoparlantes han restituido el lugar fundacional que la escritora y periodista martiniqueña Paulette Nardal (18961985) tuvo en los orígenes del movimiento de la negritud. Este artículo discute una dimensión menos explorada en su legado: el rol que jugaron las revistas que dirigió en tanto casos de transculturaciones impresas desde el punto de vista de la cultura
\end{abstract}

Este artículo fue escrito en el marco de la beca de doctorado nacional ANID 21202038 y recibió financiamiento del proyecto "Connected Worlds: the Caribbean, Origin of Modern World" del programa de investigación e innovación Horizonte 2020 de la Unión Europea en el marco del convenio de subvención Maria Sklodowska Curie n. ${ }^{\circ}$ 823846. Agradezco la lectura atenta y sugerencias de Alejandra Vega, Patricio Bascuñán, Lucia Stecher y Angelo Nárvaez a este manuscrito en sus versiones iniciales. 
material. Para ello se indaga en el carácter transformador que tuvieron respecto de los horizontes culturales, primero en París, con los impresos del internacionalismo negro del período de entreguerras, y luego en Martinica con La Femme dans la Cité (1945-1951), revista central del nuevo feminismo antillano. Se sostiene que, desde esta perspectiva, el estudio de los impresos permite reconstituir los primeros pasos de la formación de un contrapúblico subalterno antillano.

Palabras clave: cultura impresa, transculturación, contrapúblico, Paulette Nardal, Martinica, negritud.

\section{Abstract}

In the last two decades, English and French-speaking research has restored the foundational place that Martinican writer and journalist Paulette Nardal (1896-1985) had in the origins of the Negritude movement. This article discusses a less-explored dimension of her legacy: the role played by the magazines she ran as examples of printed transculturation from the point of view of material culture. It examines the transformative impact they had on the cultural horizons of the period, first in Paris, with the prints of black internationalism of the interwar period, and then in Martinique with La femme dans la cité (1945-1951), a magazine that was central to the new Antillean feminism. From this perspective, the study of the printed matter allows us to reconstitute the first steps of the formation of a subaltern Antillean counterpublic.

Keywords: Print Culture, Transculturation, Counter-Public, Paulette Nardal, Martinique, Negritude.

Recibido: 04/01/2021

Aceptado: 14/05/2021 


\section{INTRODUCCIÓN}

Entre 1918 y 1939, París fue el epicentro de una escena intelectual que en sus heterogéneas tendencias de vanguardia (surrealista, comunista, antibelicista, etcétera) se vincula al naciente internacionalismo negro (Edwards). Dicha escena, constituida al término de la Primera Guerra Mundial y que Lao-Montes ha llamado cosmopolitismo negro, participó activamente de la cultura impresa del período. Revistas, periódicos y libros fueron el resultado de un circuito que permitió la inserción en el campo letrado de escritores, escritoras y artistas procedentes de diferentes latitudes de África y su diáspora, que convergieron en la metrópolis francesa para estudiar y formarse profesionalmente. En esta escena se ubica Paulette Nardal (1896-1985), periodista y escritora martiniqueña, quien desarrolló los primeros años de su carrera profesional como gestora y escritora, tanto en periódicos autónomos como en espacios institucionales de la cultura francesa. Su trabajo, escasamente conocido y reconocido en el canon del internacionalismo negro y, posteriormente, de la negritud, fue de gran relevancia a la hora de tender puentes y diálogos interraciales inéditos y promover la circulación multilingüe de estos (Edwards, Sharpley-Whiting).

En Paulette Nardal se encuentran los primeros trazos de un imaginario común entre los pueblos africanos y afrodiaspóricos impulsado desde medios impresos. Ideas, propuestas y diálogos que apostaron por transformar los horizontes culturales, primero en París con la emblemática La Revue du Monde Noire (1931-1932) y luego en Martinica, con la dirección de la revista La Femme dans la Cité (1945-1951)³. Esta última

$2 \quad$ La Revue du Monde Noire / Review of the Black World fue cofundada y dirigida por Paulette Nardal junto con Léo Sajous en París. Trabajaron en el proyecto Andrée Nardal, Jane Nardal, Clara Shephard y Louis-Jean Finot y participaron destacadas figuras del mundo intelectual negro parisino. Fue una revista bilingüe, pionera en su formato, que dio lugar en un solo impreso a los dos idiomas principales de la literatura africana y afrodiaspórica. Esta revista fue un referente ineludible para los movimientos intelectuales posteriores, como la negritud, y fundacional en lo que T. Denean Sharpley-Whiting reconocerá como la utopía de un "Francophone New Negro" ("Femme négritude" 16).

3 La Femme dans la Cité fue una revista de publicación mensual, fundada por Paulette Nardal en Martinica. Estaba dirigida a la formación intelectual y cívica de las mujeres 
revista, la menos conocida en su trayectoria, funcionó durante seis años con un anclaje contextual específico: ser un instrumento para la formación intelectual de las mujeres antillanas recientemente incorporadas a la esfera pública con derechos políticos e identificadas por Nardal como un nuevo sujeto relevante para el escenario refundacional de Martinica. Esa coyuntura refundacional estuvo enmarcada en la declaración de la Cuarta República Francesa, que abrió paso, vía votación popular, a la departamentalización de los territorios franceses de ultramar en 1946. Para la especialista en movimientos político-culturales del Caribe francófono, Anette Joseph-Gabriel (2019), la función de Nardal no fue marginal, al contrario, se suma a un conjunto de prácticas e intervenciones políticas en el espacio público que fueron parte de un extenso proceso en que las mujeres negras, en diferentes puntos del Imperio francés, desafiaron y posteriormente transformaron el concepto de ciudadanía y de democracia que se tenía tras la Segunda Guerra Mundial.

Inscribiéndose en los debates sobre las culturas impresas (Viu, Materialidades), cultura material y transculturación, este artículo se enfoca en el rol que tuvo esta última revista para la formación de lo que Nancy Fraser ha llamado un "contrapúblico subalterno" (166) propio de las Antillas, mediante la operación específica de "transculturación impresa" ${ }^{4}$. Esta propuesta dialoga con el camino avanzado por Raphael Dalleo en torno a las esferas públicas caribeñas y enfatiza la importancia de la materialidad de los impresos en la formación de contrapúblicos subalternos. Debido a que una cultura material de los impresos antillanos implica un programa de investigación más amplio, este artículo expone una primera entrada a dicha propuesta para pensar

antillanas mediante artículos literarios, artículos de investigación cruzados por noticias contingentes que eran comentadas en el marco de la revista.

4 El subrayado en las culturas impresas en plural, propuesto recientemente por Antonia Viu, exhibe que el campo de la cultura impresa reúne un corpus de debates y líneas de investigación que cruzan la historia del libro (Chartier, Darton, Febrvre, Mollier), la historia de las revistas (Pita, Gilman, Garategaray), la historia intelectual (Palti, Tarcus, Skinner) con debates propios del campo de la cultura material (Miller, Appadurai, Douglas y Isherwood). 
desde el punto de vista de la cultura material los horizontes culturales que se estarían disputando en los impresos de Nardal en general y en La Femme Dans la Cité en particular. Para ello este artículo se divide en cuatro secciones, orientadas a i) contextualizar la trayectoria intelectual de Paulette Nardal y su exclusión del canon de la negritud, a partir de su participación en la cultura impresa del período de entreguerras y del internacionalismo negro; ii) indagar en la pertinencia de establecer cruces teóricos entre cultura impresa y transculturación para analizar el rol y el potencial de los impresos producidos en contextos de relaciones coloniales y neocoloniales activas; iii) analizar La Femme Dans la Cité en tanto impreso producido y dirigido por Nardal, cuya gráfica, secciones y organización general muestran un horizonte transculturador respecto del concepto de ciudadanía; y iv) examinar la sección de variedades "Dans la cité", cuya organización interna expone una racionalidad subyacente que prefigura el sujeto de este impreso: la mujer antillana en la ciudad asimilada.

\section{NARDAl, MÁs ALLÁ DEL CANON DE LA NEGRITUd}

La historiadora estadounidense Jennifer Anne Boittin ha llamado metrópolis colonial al prodigioso y contradictorio escenario que se forma en París en el período de entreguerras (XV). Artistas, escritores, músicos, como también discursos provenientes de los diferentes movimientos de vanguardia, vitalizaron imaginarios de reconocimiento racial, de autodeterminación política y estética en una abierta cuadratura de tensiones de género y raza que se extendieron a lo largo del siglo XX. En sus palabras: "el término colonial, en oposición a imperial, revela la agencia, o autonomía, incrustada en el acto de ocupar y utilizar los espacios de la ciudad: las mujeres blancas y los inmigrantes coloniales encontraron sus propias formas de 'colonizar' París"; de ese modo, continúa Boittin, "el imperio tomó forma en los migrantes coloniales presentes en sus calles, en los hombres y mujeres blancos que habían viajado a las colonias pero 
se asentaron en la ciudad, y en las múltiples imágenes y representaciones del imperio" (XV, traducción propia) ${ }^{5}$.

Los primeros discursos antiimperialistas, en todas sus vertientes ideológicas, constituyeron expresiones políticas de una metrópolis colonial constituida en el marco del Segundo Imperialismo. Tales discursos integraron diversos movimientos y organizaciones con tendencias disímiles -radicales y moderadas- en un marco común trazado por el internacionalismo de quienes se sintieron parte de la historia común y global de las diásporas producidas por la esclavitud en el llamado Atlántico negro (Gilroy). La posterior negritud, movimiento político-identitario, tensiona las posiciones moderadas de esta tradición y abre una tendencia inédita en el programa político de los y las sujetos racializados.

En esa metrópolis colonial, Claude McKay, Langston Hughes, Alain Locke, René Ménil, Burghardt Dubois, Léopold Sédar Senghor, Aimé Césaire, Jean Price-Mars y Maitre Jean-Louisem, entre otros, se hicieron parte de diferentes proyectos impresos conectando las experiencias del renacimiento de Harlem con el creciente orgullo negro. Todo esto en medio de un fuerte incremento de la población migrante en la Francia metropolitana después de la Primera Guerra, cuando comienzan a participar de la educación universitaria las primeras generaciones de estudiantes de ultramar ${ }^{6}$.

El canon que posteriormente se construye sobre este período invisibilizó a muchas de las mujeres que en esas fechas destacaron por sus labores de editoras, gestoras y escritoras, y establecieron verdaderos puentes fundacionales para el diálogo entre afrodescendientes de diversas

De aquí en adelante, todas las traducciones son mías.

La población extranjera en la Francia metropolitana tuvo un crecimiento sostenido a partir de 1851, y su punto más alto al término de la Primera Guerra Mundial. Porcentualmente esa oscilación fue desde un 1\% (379 personas) a mediados del siglo XIX a un 6,9\% (2.891 personas) del total de la población hexagonal hacia 1931 (Bollenot, "À bas l'exposition coloniale" 148). Esa misma curva ascendente la referencia Boittin para argumentar la complejidad del panorama migrante en París hacia esas fechas. 
procedencias ${ }^{7}$. Las hermanas Nardal - particularmente, Paulette- fueron quienes corrieron peor suerte en ese sentido. Nacen en la isla Martinica, hijas de Louise Achille - profesora y reconocida figura de la sociedad civil-, y Paul Nardal -destacado arquitecto-, crecen en un entorno de alta cultura propiciado por sus padres. Su casa en Forte-de-France recibía la visita constante de intelectuales y destacados músicos locales, era un espacio de contacto permanente con la creación desde muy temprana edad (Musil 378). Andrée, Jane y Paulette sobresalieron entre las siete hermanas por su vínculo con la escritura y el periodismo. En los primeros años de la década del veinte, cuando se trasladaron a París, comienzan a frecuentar el circuito intelectual y artístico e inauguran el influyente salón Clamart, ubicado en el número 7 de la rue Hébert del barrio homónimo. El salón, que físicamente ocupaba las dependencias de su propia casa, se volvió un lugar de tránsito habitual para quienes se reconocían identitariamente como parte de una comunidad de artistas africanos y afrodescendientes en la metrópolis francesa. Desde el salón se imaginaron proyectos, periódicos e ideas movilizadas por los encuentros, tertulias y sesiones de conversación que habrían dado origen a las primeras ideas que convergieron en lo que hoy conocemos como negritud (Sharpley-Whiting; Jennifer Boittin).

La negritud que pasó a la historia como un concepto acuñado y difundido por Aimé Césaire, Leopold Senghor, León Damas, y posteriormente debatido y resignificado en diversos momentos del siglo XX (Depestre), habría aparecido por primera vez en los escritos de las Nardal y, en particular, de Paulette, la hermana mayor, quien fuera la primera mujer negra en estudiar en la Sorbona, y autora de una serie de artículos y publicaciones, incluida una tesis sobre La cabaña del tío Tom, con la que obtuvo el grado de licenciada en letras en 1928. En relación con el concepto de negritud, Paulette Nardal señala en sus memorias que "con ese descubrimiento del orgullo negro, escribí en diversas revistas que me permitieron expresar mis intuiciones, y estas han servido para

Los trabajos de Sharpley-Whiting, especialmente Negritude Women, han sido clavespara la reconstrucción de la historia de las mujeres en la fase formativa de la negritud. 
la eclosión de un movimiento (la negritud). Yo insisto sobre esa palabra intuición", y luego agrega, "es por eso que he usado la expresión 'seguir la inclinación de mi temperamento'. El orgullo negro me surgió después de haber escuchado los espirituals negros y frecuentado músicos e intelectuales norteamericanos" (Nardal citada en Grollemund 30).

La exclusión de las hermanas Nardal de la historia de la negritud, y las consecuencias que eso tuvo desde el punto de vista del cruce raza/ género, interroga directamente los regímenes de legitimación y de autorización que rigen los procesos de configuración de un canon. Dicha marginación también se expresó en el tardío reconocimiento de Paulette Nardal como intelectual en Martinica. Su distancia con el comunismo caribeño la habría marginado de facto de los espacios orgánicos en la misma isla, salvo el que correspondía al primer feminismo antillano, que tuvo una expresión particularmente importante en Martinica y Guadalupe y donde Nardal poseía el reconocimiento de sus pares ${ }^{8}$. Su actividad pública estuvo fundamentalmente abocada a la formación de las mujeres y a la difusión de un feminismo cercano, aunque no doctrinalmente comprometido, a un cristianismo humanista ${ }^{9}$. Probablemente su posición

8 Con primer feminismo antillano me refiero en este artículo al movimiento de mujeres que se organiza en torno a la aprobación del voto femenino universal en las Antillas francesas. Más allá de discutir aquí las olas o etapas del feminismo y su pertinencia para la región, es relevante señalar la relación contextual y política que surge entre la nueva ciudadanía aparecida con la departamentalización de los territorios de ultramar y los desafíos que presenta la primera elección en que participan mujeres. Si bien dicha articulación constituye un asunto que requiere una investigación particular, es necesario resaltar que, tanto en Martinica como en Guadalupe, más allá de la posición de Nardal, existió una fuerte alianza entre feminismo y comunismo con gran potencial estratégico. Esa alianza en Guadalupe, por ejemplo, llevó al triunfo a su propia representante a la Asamblea Nacional Francesa, Gerty Archimède, quien ejerció su cargo de manera contemporánea a Aimé Césaire. Si bien Nardal no fue la única figura al alero de una asociación o gestora de esas alianzas, sí tenía el reconocimiento de sus contemporáneas y fue muy reconocida desde la isla vecina, Guadalupe (Palmiste). Por su parte Nardal deja entrever en sus memorias que su distancia con el comunismo sería una de las causas por las que habría sido marginada del canon.

9 No me detendré mayormente en las filiaciones ideológicas de Paulette Nardal que son trabajadas por Sharpley-Whiting (Beyond Negritude) y en la tesis doctoral de Eve Gianoncelli. 
de eslabón perdido en la historia de la negritud responde en parte a estos motivos y a que su trayectoria tuvo una tardía aparición en la historia escrita de esas genealogías: "Yo sé que Lilyane Kesteloot nos ha hecho justicia en señalar el rol de La Revue du Monde Noire y de nuestro 'salón literario' en la evolución de las ideas brillantemente expuestas y apoyadas después por Césaire y Senghor", sin embargo, "hace mucho tiempo que mi hermana Jane y yo debimos escribir nuestras memorias para recordar nuestra acción que ha pasado mucho tiempo en silencio" (Nardal citada en Grollemund 96).

Más allá del interés histórico de interrogar el canon de la negritud y la extensión de sus propios mitos fundantes, como ya lo han hecho numerosas investigaciones desde el espacio académico anglo y francoparlante (Musil, Sharpley-Whithin, Boittin, Bruneel y Gomes, Gianoncelli, Edwards), aquí nos interesa indagar en algunas preguntas sobre los proyectos impresos a partir de la trayectoria de Nardal. ¿Qué rol cumplieron sus impresos en el campo cultural? ¿Cómo negociaba las dimensiones de autonomía y heteronomía en la producción de estos periódicos? ¿En qué medida pueden entenderse como dispositivos transculturadores? ¿Qué aspectos de esas publicaciones son relevantes para pensar el rol transculturador de impresos que circulan públicamente en situaciones de dependencia colonial?

De Nardal se conoce principalmente su etapa parisina y su vínculo con La Dépêche Africaine ${ }^{10}$ y La Revue du Monde Noire. Entre quienes investigan su trayectoria (Boittin, Boni, Musil), bastante menos atendido es el período de su retorno a Martinica, que además coincide con el de Aimé Césaire y Suzanne Césaire ${ }^{11}$. En medio de la preparación de las primeras votaciones populares para que Martinica se convirtiera en Departamento francés de ultramar, Paulette Nardal funda la revista mensual La Femme dans

\footnotetext{
10 La Dépêche Africaine fue un periódico bimensual operativo entre 1928-1932, principal órgano impreso del CDIRN (Comité de Defensa de los Intereses de la Raza Negra). En este periódico, las hermanas Nardal publicaron artículos, textos literarios y crónicas.

11 En los trabajos recientes de Demougin y Gianoncelli existe una mayor preocupación por articular la etapa parisina con la martiniqueńa.
} 
la Cité. Estas votaciones no solo fueron decisivas para la reconfiguración del pacto colonial de la Francia hexagonal con los territorios de ultramar, sino que además fueron las primeras elecciones que se celebraron con el recién obtenido voto universal femenino en Francia en 1944. Es así como la nueva revista de Nardal se publica con un explícito doble propósito: preparar a las mujeres locales para su participación en la esfera pública y los diferentes ámbitos de la vida cívica; pero también para inaugurar un instrumento impreso en Martinica desde el cual fuera posible imaginar la ciudadanía como un horizonte abierto a las necesidades de la época.

En las páginas de La Femme dans la Cité puede advertirse que la nueva tarea editorial de Nardal no fue menos ambiciosa que las anteriores. La revista sale a la luz el 1 de enero de 1945 (ver imagen 1), con un sello de moderación internacionalista atravesado por una línea gráfica que proyecta a sus lectoras un imaginario conciliador: en su primera página resalta el escudo de una mujer y su hija, metáfora del lazo materno entre la madre patria y las nuevas ciudadanas (Sharpley-Whiting, Beyond Negritude) que acompañará con escasas modificaciones todos sus números.

Si bien este proyecto es el menos estudiado entre sus revistas, su anclaje histórico, su duración en el tiempo, su regularidad y filiación con una lectoría estable lo vuelven un objeto privilegiado para abordar el problema de la transculturación de los impresos. La Femme dans la Cité fue una vitrina de agitación y un dispositivo de modernización para la formación política e intelectual de un nuevo sujeto social recién aparecido: la mujer con derechos políticos. Pero por más universal que se planteara el periódico de Nardal, es un impreso dirigido a una mujer particular: la mujer asimilada en la ciudad franco-antillana. Ahora bien, antes de abordar el carácter específico de este impreso, es necesario precisar el punto de vista teórico desde el cual lo abordaremos. 


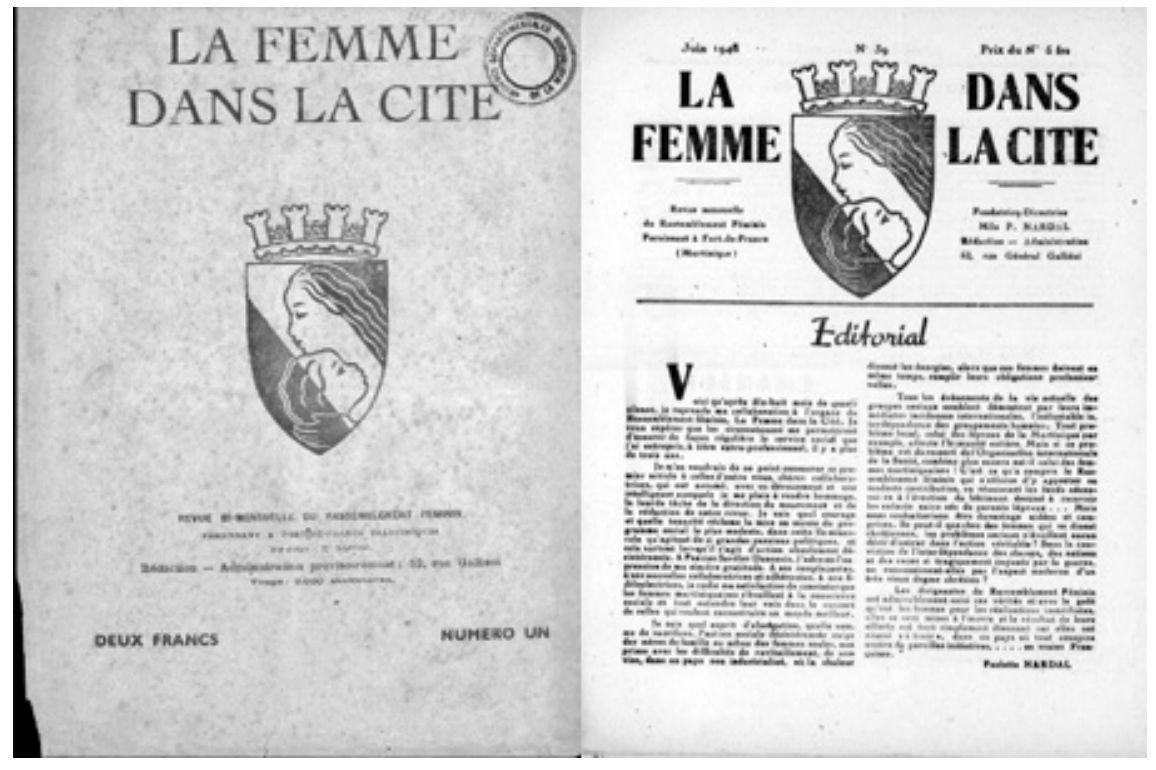

Imagen 1: La Femme dans la Cité, 1945, Archivo digital Biblioteca Nacional de Francia.

\section{CULTURA IMPRESA Y TRANSCULTURACión EN CONTEXTOS DE RELACIONES COLONIALES}

Hablar de impresos es hablar de producción, pero también de un conjunto de relaciones sociales (materiales y simbólicas), de circulación y de consumo. ¿Por qué producir un impreso? ¿Por qué consumir un impreso? ¿Cuáles son las motivaciones detrás de ambas acciones? El enigma de la demanda, presente en los primeros estudios sobre cultura y consumo, adquiere aquí un espesor particular (Douglas e Isherwood). No es posible separar un impreso, en tanto mercancía, de sus condiciones materiales y del sistema de relaciones simbólicas que anuda ${ }^{12}$. Tampoco de los elementos de distinción

12 Douglas e Isherwood hacen los primeros esfuerzos por pensar antropología y economía en conjunto para desmitificar las ideas de consumo. Comprenden las mercancías como señales de las categorías racionales, que en su conjunto representan una serie más o menos coherente y deliberada de significados, que podrán ser percibidos solo 
(Bourdieu) que ofrece la elección entre una mercancía impresa y otra. El consumo de impresos promete capitales específicos que su industria procesa, y que no son solamente conocimiento, entretención o alta cultura ${ }^{13}$. Con mayor o menor tecnología a disposición, los impresos responden a una trama social de producción que anuda en un arco perfectamente ensamblado a escritores, editores, imprenteros, comercializadores, libreros y lectores (Darnton, “¿Qué es la historia del libro?”).

Un impreso implica la idea de producto o mercancía, pero también de costos específicos, de circulación y de rentabilidad para su reproducción. Robert Darnton ha mostrado magistralmente en The Business of Enlightenment cómo la enciclopedia se convirtió en un negocio excepcional en su época por la alta ingeniería de su estructura productiva, que logró producir balances insólitamente provechosos en la relación capital y trabajo (226). Pero no todos los impresos son enciclopedias. El revés de ese modelo corre como un fantasma en la mayoría de los proyectos que no logran encontrar su propia fórmula de sostenibilidad. La precaria dimensión comercial de la trama social descrita por Darnton cruza la historia de proyectos impresos en general, una precariedad que Víctor Goldgel ha mostrado detalladamente en los casos de Cuba, Chile y Argentina de mediados del siglo XIX (93-4). Porque si no es mediante su propio negocio o una ingeniería económica de sostenibilidad -como en el caso de la enciclopedia o del sistema de best-seller en el mercado editorial transnacional contemporáneo-, un impreso (periódico, revista o libro) requiere de un subsidio o financiamiento externo.

Desde esta perspectiva, se puede reconocer que la cultura impresa vinculada al internacionalismo negro parisino del período de entreguerras fue en gran medida una cultura impresa subsidiada. Una porción importante

por quienes conozcan el código y los escudriñen en busca de información. Para ellos, la idea misma de consumo debe ser puesta en la base del proceso social.

13 Resulta provechoso pensar el consumo de impresos desde el punto de vista del consumo cultural trabajado por Bourdieu. Más que identificación gruesa del consumo de impresos como consumo cultural, lo interesante aquí es por qué se da el consumo de un tipo impreso en vez de otro, o bien qué negocia esa mercancía, o qué público lector construye un impreso cuando se toma una u otra decisión editorial. 
fue financiada por el Ministère des Colonies (Ministerio de las Colonias), como señala Boittin en Colonial metropolis, sin profundizar mayormente en este asunto (151-2). Este ministerio -fundado para encargarse de los asuntos correspondientes a la administración de las colonias del Imperio francés (d'Andurain) - también financió la controversial Exposición Colonial de 1931, que estuvo durante cinco meses montada en el barrio obrero del XXe Arrondissement y que despertó grandes debates por sus pabellones temáticos -dedicados a Marruecos, Argelia, Martinica y Guadalupe, entre otros-, que simulaban a escala las posesiones del Imperio en sus territorios de ultramar. Esas controversias fueron públicas y organizadas por un grupo heterogéneo de antiimperialistas (Bollenot, "Ne visitez pas") en cuya alianza también aparecieron los surrealistas europeos (Breton, Éluard, Péret, Sadoul, Aragon y Char, entre otros) con quienes difundieron su manifiesto Ne visitez pas l'exposition colonial y levantaron la contraexposición La vérité sur les colonies. Los jóvenes estudiantes antillanos, africanos y asiáticos que vivían sus primeros años de politización y actividad intelectual en el centro metropolitano, si no fueron parte de esas controversias, absorbieron los debates que allí se fraguaron (Toledo 125-6; Bollenot, "Ne visitez pas" 74).

La procedencia gremial e institucional de estos financiamientos no es un dato menor, ya que estamos hablando de una cultura impresa que posee una orientación ideológico-crítica, que en algunos casos recibe financiamiento directo de las instituciones coloniales. Las tensiones entre estos proyectos y sus fuentes de financiamiento por cierto existieron, incluso la dependencia absoluta de tales recursos. Esto se expresa, por ejemplo, en que la publicación de La Revue du Monde Noir, luego de seis números acaba abruptamente en 1932 por la suspensión de recursos. $\mathrm{O}$ que los jóvenes editores martiniqueños de Légitime Défense en París, revista inaugural del surrealismo marxista antillano, solo llega a tener un número publicado porque fue desfinanciada, situación que implicó para sus jóvenes editores la pérdida inmediata de las becas con que estudiaban (Toledo 120). Esta interdependencia no solo se dio en la Francia metropolitana. Unos años después, en Martinica, las ideas y posicionamientos que 
Aimé Césaire, Réne Ménil y Suzanne Césaire presentaron en Tropiques, la revista literaria más importante de la isla entre 1941-1945, habrían despertado tantas molestias en la administración colonial que para el número 8 se confiscó el papel con el propósito de boicotear la salida de imprenta (Sharpley-Whiting, Negritude Women 90) ${ }^{14}$.

El origen de las fuentes de financiamiento o subsidio no le resta importancia al rol que tuvo la cultura impresa en el activismo intelectual negro, pues se reconoce en ella un claro editorialismo programático (Beigel), es decir, una articulación entre trabajo editorial y horizonte ideológico-político, similar al que puede advertirse en la cultura impresa de las vanguardias históricas y latinoamericanas (Schwartz). La cultura impresa del cosmopolitismo negro, por un lado, levanta un programa en torno al orgullo negro (Fierté noire) cuya utopía era inaugurar un horizonte común, multilingüe, multirracial entre los pueblos africanos y las diásporas afrodescendientes, y, por otro, convive orgánicamente con el conjunto de impresos que circulaban en la época como un subsector de la producción. Los financiamientos institucionales también existieron para proyectos como Les Annales Coloniales y La Chronique Colonial, de alta sofisticación gráfica, donde intelectuales de la escena cosmopolita negra, como Paulette Nardal, colaboraron.

Quienes ejecutaron estos proyectos de publicaciones utilizaron la tecnología de estos impresos como un dispositivo efectivo para reunir un amplio espectro de actores y creadores del presente, pero también para inaugurar un diálogo, hasta ese entonces inédito, en los medios escritos. Paulette Nardal está entre quienes mejor comprendieron el potencial de esa interlocución vehiculizada a través de los impresos. Ella operó como una suerte de diplomática o mediadora interracial que dialogó constantemente con posiciones contrarias. Media entre su propia esfera intelectual negra (su club d'amis) y la escena parisina en general. Su

14 La autora desarrolla con mayor detalle este asunto, asumiendo que ese hecho sería expresión de la potencia de oposición que tuvo la revista martiniqueña hasta el cierre de su redacción en 1945, año de las elecciones, en que Césaire comienza a ser una figura completamente pública y Suzanne Césaire publicaría su último escrito. 
colaboración como periodista y editora en publicaciones del Ministerio de las Colonias en paralelo a su colaboración en La Dépêche Africaine, Le Cri des Nègres, Le Soir y su codirección de La Revue du Monde Noire, así lo demuestran. Por ejemplo, en sus artículos en Les Annales Coloniales (ver imagen 2) describe diferentes aspectos costumbristas de las Antillas, torciendo el imperativo del exotismo con descripciones enfocadas a resaltar la complejidad y riqueza cultural de sus sociedades.

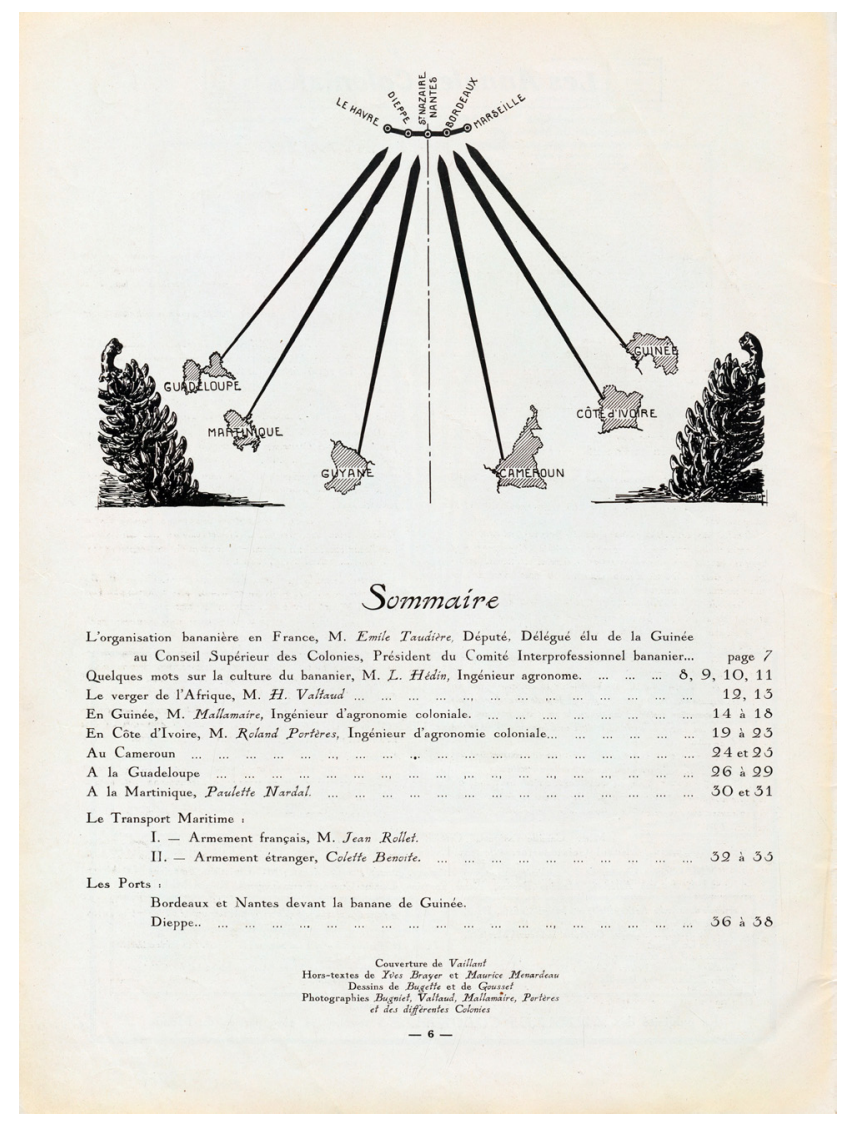

Imagen 2: Les Annales Coloniales, 1935, archivo digital Biblioteca Nacional de Francia. 
Ese esfuerzo por interceder entre el exotismo y la representación positiva de la isla se observa en la guía turística que realizó sobre Martinica en el marco de la Exposición Colonial de 1931. La guía, en tanto impreso de consumo y objeto lujoso en su factura y recursos gráficos (en un formato de bolsillo de $16 \times 11 \mathrm{~cm}$ logra incluir mapas, fotografías y referencias enciclopédicas sobre las Antillas), incorpora acuciosas descripciones geográficas y humanas escritas por la misma Paulette Nardal. Lejos de reproducir las estrategias de alterización propias de los imaginarios orientalistas sobre las Antillas, caracteriza la diversidad y la potencial asimilación de estos territorios de ultramar utilizando los recursos narrativos de la novela de viajes (ver imagen 3). Así relata, por ejemplo, tipos raciales de la isla: "El turista podrá observar en su variedad todos los tipos provenientes del cruzamiento de muchas razas, tipos igualmente interesantes desde el punto de vista artístico"; y, más adelante, "entre la negra color de vainilla y la mulata de tipo latino, él verá los matices casi imperceptibles, él verá pasar toda la riqueza de tonos de madera preciosa, la capresse [sic], color de sapote, el rubio amargo de la chabine ${ }^{15}$, la tez de Andaluza, Maure, del Hindú y de China" (Guide 4).

Paulette Nardal reconoce el potencial paradójico de esos impresos oficiales y de los otros impresos contraculturales. En sus textos, desordena los imaginarios y representaciones exotistas, media entre estos y sus lectores $y$, de ese modo, se posiciona en un lugar bisagra del campo intelectual. Su participación formal en la esfera cultural institucional y el rol activo en una cultura impresa del internacionalismo negro la sitúan en un lugar de negociación. La posibilidad de disputar sentidos y horizontes culturales mayores al tiempo que se utilizan los recursos institucionales comienza, entonces, a ser parte de su oficio. Pero Nardal no altera la lógica general de producción y circulación de esos impresos/mercancía, más bien en ese marco (el de la cultura impresa de su período) amplía

$15 \quad$ En las Antillas francesas se llama capresse a la descendencia entre una persona negra y una mulata. El sapote es un fruto, y chabine se le dice a los hijos de mulatos que posee piel y ojos claros con cabellos rubios o colorines. 
las posibilidades de diálogo, de representación y transformación de los horizontes culturales con mayor o menor éxito.

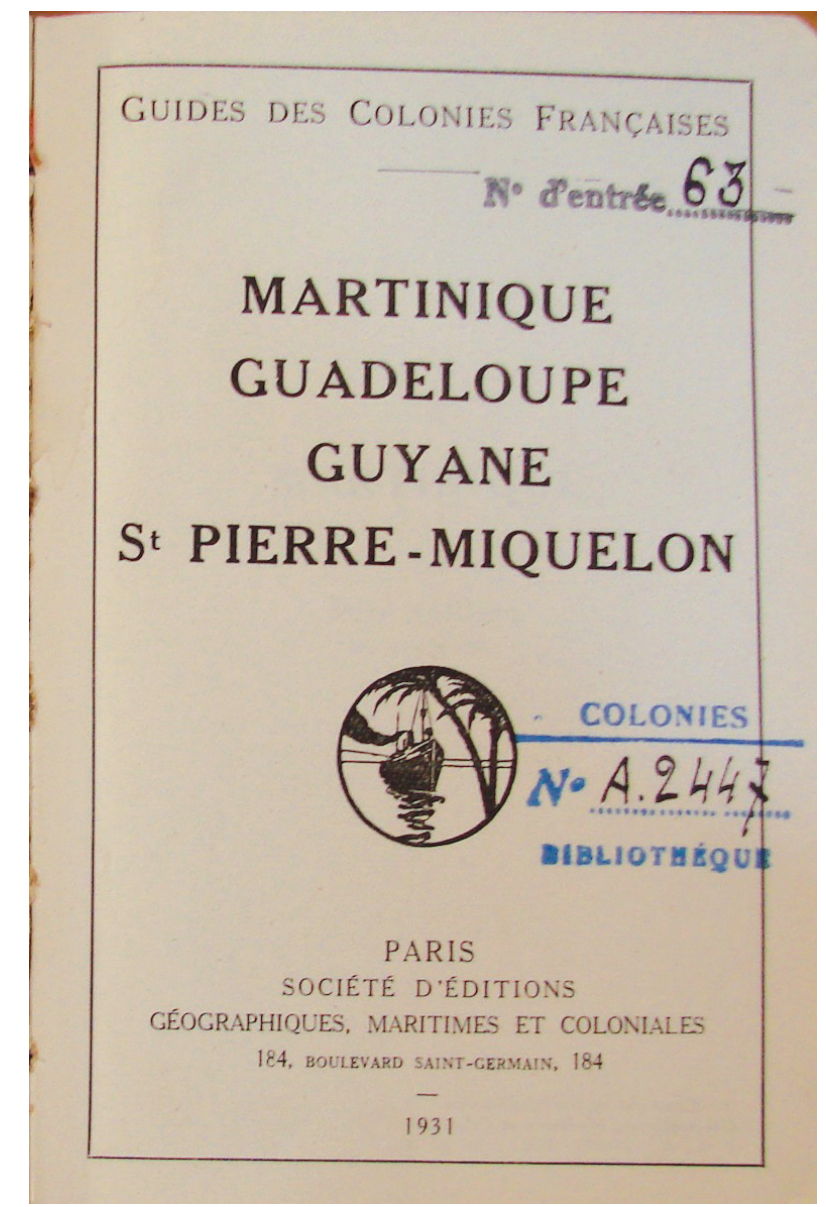

Imagen 3: Guía turística. Martinique, Guadelupe, Guyane, St Pierre-Miquelon, 1931, archivo digital Biblioteca Nacional de Francia.

En ese sentido, resulta necesario reflexionar acerca de cómo estos impresos, producidos en el contexto formativo de un contrapúblico feminista en las Antillas, cumplieron un rol transculturador. Una transculturación 
pensada a partir de lo que Fernando Ortiz propuso en su Contrapunteo cubano del trabajo y el azúcar como categoría explicativa de la historia cubana: "la verdadera historia de Cuba es la historia de las intrincadísimas transculturaciones" (93). Ortiz, además de ofrecer con su neologismo un camino para superar las miradas dicotómicas y antiprocesuales de la aculturación, la desculturación, exculturación, inculturación, etcétera, se propone pensar en contrapunto, por un lado, el modo de producción específico de las dos grandes mercancías cubanas (el tabaco y el azúcar) $\mathrm{y}$, por otro, las disposiciones sociales y prácticas culturales que derivan de su circulación y consumo.

Los impresos periódicos han sido para la crítica cultural el objeto privilegiado para el estudio de las esferas públicas modernas (Goldgel). El trabajo de Ortiz -que puede considerarse una investigación de cultura material avant la lettre ${ }^{16}$ - nos ayuda a aproximarnos de un modo situado a la producción de impresos en contextos de relaciones coloniales y neocoloniales contemporáneas desde los horizontes culturales que abrieron. Ortiz muestra el impacto cultural del tabaco y el azúcar en tanto mercancías producidas en un contexto de relaciones económicas y culturales específicas. No se detiene en las rutas y términos de intercambio de un circuito comercial marginal o contrahegemónico, tampoco en las rutas y desvíos específicos que Appadurai investiga para pensar contextos mercantiles que producen subáreas regionales del capital global con sus particularizados términos del intercambio -un trabajo muy relevante para pensar los circuitos de circulación de las mercancías más allá de su relación global con las rutas mercantiles globales (31-3)-. El problema del tabaco y el azúcar para Ortiz se enfoca en desentrańar el misterio de cómo un mismo modo de producción y la forma social en que esas mercancías se producen, pueden desencadenar procesos de transculturación diferentes y además desplegar implicancias

\footnotetext{
16 La sugerencia de inscribir a Ortiz en el campo de teorías sobre la cultura material es una propuesta de la historiadora chilena Alejandra Vega. Por su parte, la académica Antonia Viu, en su trabajo sobre la revista Orígenes, reconoce los antecedentes y materiales con que el antropólogo cubano llegó a su teoría de la transculturación a partir, a su decir, de una "revista de revistas" ("Como rebrote ..." 90).
} 
culturales completamente distintas. El antropólogo cubano piensa el arco completo de este recorrido, es decir, las implicancias de que una orientación de la producción (sus relaciones sociales y económicas, su facturación, su técnica) conduzca un consumo específico y que, en consecuencia, dicho consumo implique disposiciones culturales abstractas: por ejemplo, cómo el consumo del tabaco en Europa se vuelve una transculturación del rito de bienvenida, de cofradía, amistad o confianza en las Américas. En ese sentido, para su programa de investigación no solo importa cómo la producción del azúcar llegó a ser hegemónica en América, sino también cómo la singularidad del tabaco impactó de manera transculturadora en Europa. Es decir, el trayecto con que un mismo modo de producción (capitalista o mercantil), un mismo circuito comercial para esas mercancías, despliega implicancias culturales diferentes debido a las transculturaciones internas que se suceden a través de las rutas de circulación y consumo específicas.

Si el tema que nos preocupa respecto de los impresos estriba en su impacto cultural en tanto mercancías (con valor, manufacturación, factura, rutas de circulación específicas) nos es posible realizar un paralelo de la teoría de la transculturación en función de estos objetos. De la mano de ciertas discusiones del campo de la cultura material (Appadurai, Miller, Douglas e Isherwood), es posible indagar cómo los impresos de Nardal participan de la cultura impresa de su período a la vez que tensionan (y en el caso de La Femme dans la Cité, transforman) los horizontes culturales de su época, particularmente en cuanto a la reimaginación del concepto de ciudadanía desde un contexto formativo del contrapúblico feminista antillano. Nardal posee la experiencia y el oficio adquirido en el contexto parisino de entreguerras, y lo traslada a Martinica con un horizonte programático. Es la experiencia de la producción de impresos en la formación de contrapúblicos lo que Nardal vehiculiza desde la escena intelectual parisina a la Martinica poscolonial. La pregunta que nos podemos plantear entonces, siguiendo a Ortiz, es si la historia cultural de las Antillas francesas poscoloniales puede pensarse desde la intrincadísima historia de sus transculturaciones impresas. 


\section{LA FEMME DANS LA CITÉ, UN IMPRESO PARA LA NUEVA CIUDADANA}

Paulette Nardal regresa a Martinica en 1941. Llega después de estar un año hospitalizada en Londres tras un accidente en el barco en el que viajaba en medio de la Segunda Guerra mundial ${ }^{17}$. Su recuperación social e intelectual de ese accidente, que podría haberle costado la vida, duró algunos años. Si bien su reincorporación a la vida pública en las Antillas nunca fue tan exigente como la de los agitados años del salón Clamart, logró prontamente un protagonismo destacado. Movilizada por la aprobación del voto universal femenino en Francia y la inminente departamentalización de las Antillas francesas, Nardal funda Le Rassemblement Féminin (1944), movimiento de mujeres de posición moderada y orientación cristiana. Aunque no fue la única organización de mujeres en Martinica -en esos mismos años Jeanne Léro crea la Union des Femmes de la Martinique (UFM) de orientación comunista- Paulette Nardal se distingue por su revista La Femme dans la Cité.

Esta revista tuvo en su inicio cuatro páginas, pero llegó a tener dieciséis. Fue redactada en la oficina de la calle Général Galliéni, impresa y producida en la Imprimirie Bezaudain, ambos lugares ubicados en la capital de Martinica, Fort-de-France. En los seis años de publicación, su tiraje mensual varió entre las 2.000 y 1.100 copias, revelando la constancia de una lectoría que no bajaba de las mil personas. Su sistema de financiamiento era mixto, poseía un apoyo económico institucional y la recaudación que provenía de suscripción de lectoras ${ }^{18}$. Cada número costaba entre $2 \mathrm{f}$ y $5 \mathrm{f}$ en su primer período, $25 \mathrm{f}$ y $40 \mathrm{fla} \mathrm{suscripción} \mathrm{anual}$

17 Estos datos biográficos de Paulette Nardal son tomados de sus memorias, Fiertés de femme noire, resultado de un conjunto de entrevistas que mantuvo con Phillipe Grollemund en la década del setenta.

18 Nardal, en sus memorias, señala que, además de las suscripciones, sus proyectos siempre tuvieron financiamiento de la prefectura de Martinica. Sin embargo, el mismo periódico en el año 1951, en el marco la celebración de los 25 ańos de la Union Féminine Civique et Sociale de París, aparece como brazo de ultramar del movimiento metropolitano. Lo que se desprende de sus memorias es que esa filiación más bien fue estratégica y no parte de sus orígenes. Nardal señala una "inspiración" en el movimiento metropolitano (109). 
en el segundo ${ }^{19}$, y se organizaba en tres grandes secciones: el editorial de Paulette Nardal, que luego de algunos números pasó a estar en la portada; una compilación de artículos temáticos -firmados a veces a nombre completo y otras solamente con iniciales: Mlle Macni, Hélène Durand (H. D.), Arabelle, A. Eda-Pierre y Marié Berté (M. B.), entre otras-, intercalados con poesía o canciones populares en créole; y la sección de variedades "Dans la cité" [En la ciudad]. Con una bajada de página que versa "La femme dans la cité salue sa marraine, la presse martiniquese" [La mujer en la ciudad saluda a su madrina, la prensa martiniqueña], la revista en su primer número reconoce su lugar en el espectro de impresos de su momento. El editorial firmado con las iniciales "P. N.", comienza preguntando:

¿Se puede deplorar el acceso de la mujer martiniqueña a la categoría de ciudadana? El futuro nos lo dirá. Pero una cosa es cierta: una revolución se acopla actualmente en nuestros espíritus. Un llamado ha sido lanzado al que algunas inteligentes, dinámicas, han respondido. (La Femme, n. $\left.{ }^{\circ} 1,2\right)$

Esa petición de autorización para la toma de la palabra, reforzada por su pie de página, desaparece prontamente y abre paso a la repetición insistente de que las mujeres de Martinica comprendan la envergadura de este llamado histórico y se preparen para la nueva ciudadanía. Particularmente, la afirmación de una revolución en los espíritus se torna un tópico que acompaña los editoriales y los artículos interiores y confluye en el llamado a un apoyo irrestricto de las mujeres a la departamentalización (Grollemund 114).

Tras las elecciones, y luego de constatarse la baja participación electoral de las mujeres en las Antillas francesas, Nardal acepta integrar la Comisión Económica y Social de la ONU en Nueva York, cargo en el que estuvo desde 1946 a 1948 y en el que escribió el primer informe sobre el rol

$\overline{19}$ Corresponde a los siguientes según el euro actual: 0.003 / 0.007 / 0.038 a 1945 aprox. 
de las mujeres en las colonias francesas (Palmiste 19) ${ }^{20}$. Esa participación volvió a internacionalizar su trabajo político-intelectual -ya no desde su gestión en el salón Clamart de París, sino desde la redacción de La femme dans la cité en Fort-de-France- a partir de debates con proyección global. Esta revista no solo cumple una función ideologizadora local, también reanuda discusiones que competen a los territorios metropolitanos e insulares, reactiva diálogos interraciales entre los territorios de ultramar y los centros metropolitanos con una perspectiva internacionalista.

Ahora, más allá de sus orientaciones ideológicas, ¿cuál fue el horizonte transculturador de este impreso? ¿Cómo vehiculiza esos propósitos? En términos de su materialidad, La Femme dans la Cité no fue una revista de vanguardia al modo de La Revue du Monde Noir u otros impresos parisinos del primer cosmopolitismo negro. La Revue du Monde Noir presentaba una apuesta sumamente moderna -a la usanza de ciertas derivas cubistas y art decó- para responder a sus propias necesidades: todos sus artículos diagramados a dos columnas para resaltar el diálogo bilingüe, las ilustraciones figurativas de su interior expresan una abstracción de las formas y los detalles geométricos de impresión referían a símbolos comunes de un imaginario afrodescendiente (ver imagen 4).

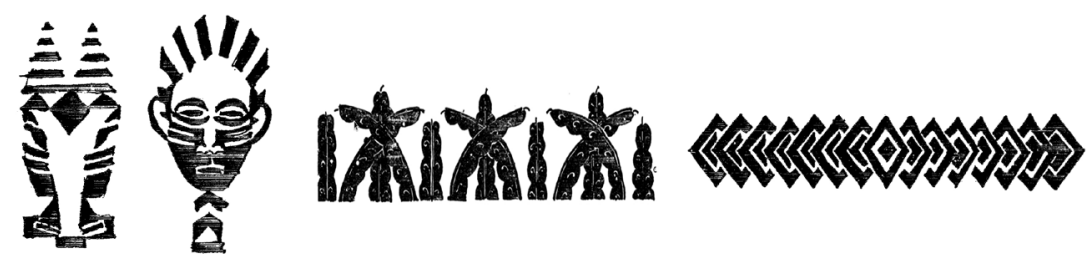

Imagen 4: Detalles de diseño La Revue du Monde Noire, archivo personal.

$20 \quad$ Si bien las elecciones se efectuaron con éxito, la tasa de participación de las mujeres en Martinica fue una de las más bajas de las Antillas francesas: 36\% en Martinica, 51,9\% en Guadalupe, muy por debajo ambas del promedio nacional (71,9\%) (Palmiste 13). Esto fue preocupante para Le Rassemblement Féminin. 
Un caso más radical en ese sentido es la apuesta vanguardista de Légitime Défense expresada en su composición ortogonal, y una composición tipográfica montada a colores planos de negro sobre rojo, que recoge los planteamientos de la nueva tipografía y de la Bauhaus (Bascuñán), y guarda una afinidad con los planteamientos del arte geométrico y constructivo (ver imagen 5).

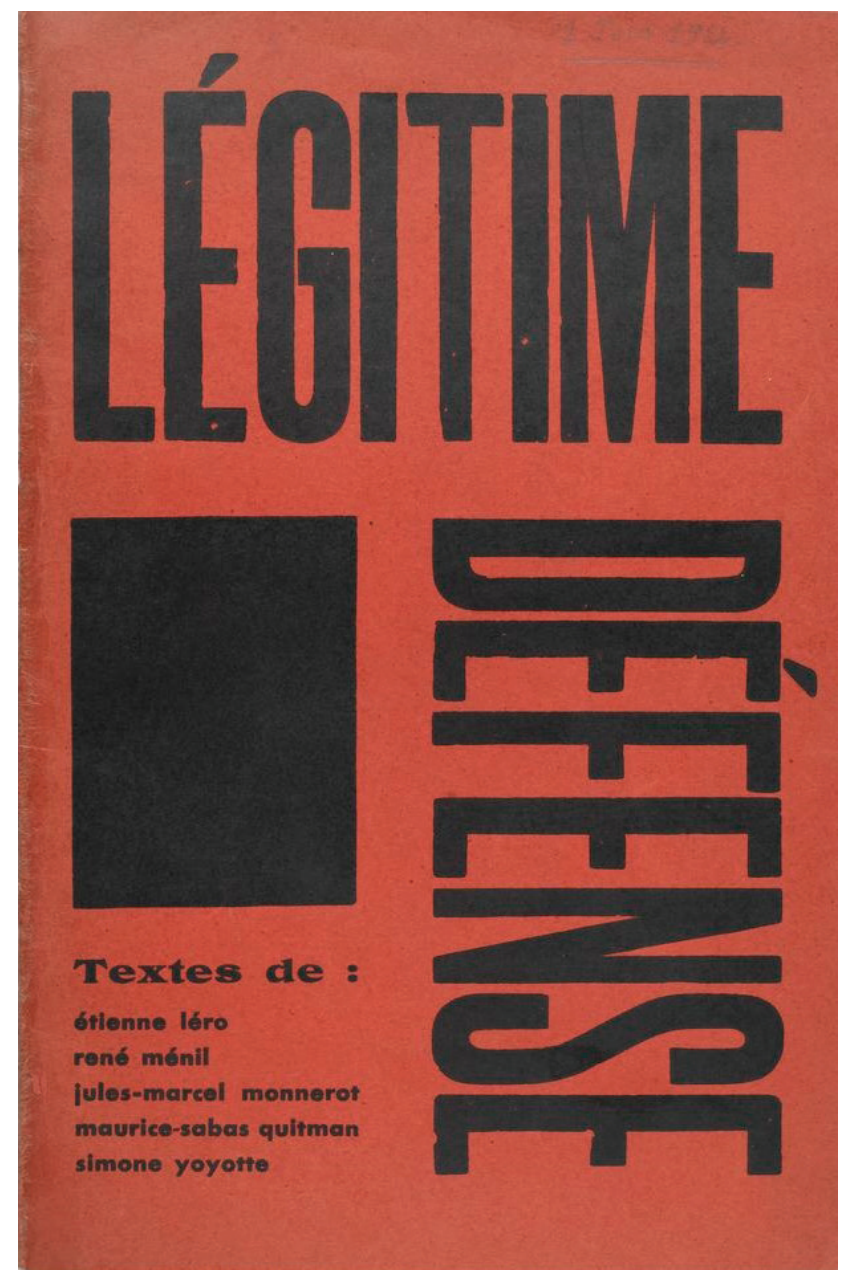

Imagen 5: Légitime Défense, archivo personal. 
La Femme dans la Cité, a pesar de publicarse casi una década después, está fuera de ese espectro de referentes gráficos, por tanto, no persigue una propuesta vanguardista en términos estético-políticos. El interés que despierta el impreso antillano de Paulette Nardal refiere a su condición inaugural respecto de cómo el objeto impreso modela y proyecta un destinatario/a emergente: la mujer antillana en la ciudad con derechos políticos. Con esa vocación ideológica la revista pareciera crear su propio registro gráfico con los recursos materiales disponibles en la isla. Si bien $\mathrm{La}$ Femme dans la Cité sigue las claves de la prensa moderna en su estructura (informativa, de opinión, contingente, vitrina de artículos temáticos y de entretención), orientada por los conocimientos previos de Nardal, ofrece una estética conciliadora que proyecta un perfil internacionalista. Esto puede observarse en la convivencia de estilos eclécticos en su diseño, donde se yuxtapone el escudo maternal del inicio con recursos de otro repertorio para la organización de sus páginas y secciones interiores, particularmente destaca el híbrido montaje tipográfico que tensiona la portada y los interiores. Esa hibridez visual permite que la revista se desprenda de una filiación nacional. Además, en la revista tampoco aparecen resabios de los célebres símbolos exotistas coloniales que Nardal muy bien conocía, como el escudo de la isla/palmera presente en la portadilla de la Guide des colonies. Muy lejos está del barroquismo visual de Les Annales Coloniales. Probablemente ajustada a sus posibilidades técnicas de impresión y producción tipográfica de la Martinica de la época, esta revista proyecta su propio camino. Porque más allá de la posibilidad de interpretar su apuesta gráfica como un resultado de las restricciones materiales que pueden haber existido en las imprentas de las Antillas, a lo largo de sus números existen reconocibles variaciones de la composición que dan cuenta de una elección intencionada. Por ejemplo, el giro tipográfico y de composición que exhibe el número especial de abril de 1948, cuando se celebra el centenario de la abolición de la esclavitud en las Antillas (ver imagen 6), una gráfica afín a la racionalidad científica y el ímpetu internacionalista de las vanguardias, probablemente influenciada por el trabajo de tipógrafos y artistas como Jan Tschichold, El Lizzitsky o Herbert Bayer. 
Una mirada a otras publicaciones martiniqueñas de la época, impresas en la misma imprenta Bezaudin, no muestran tales recursos gráficos, tampoco el eclecticismo de la revista de Nardal, expresado en la alternancia tipográfica o en el juego en el uso de cajas de texto. Considerando esas variaciones es que se puede sostener que La Femme dans la Cité utiliza un repertorio gráfico que, por un lado, refuerza su filiación internacionalista y, por otro, construye un significante ecléctico para proyectar las filiaciones de esa mujer emergente en la ciudad.

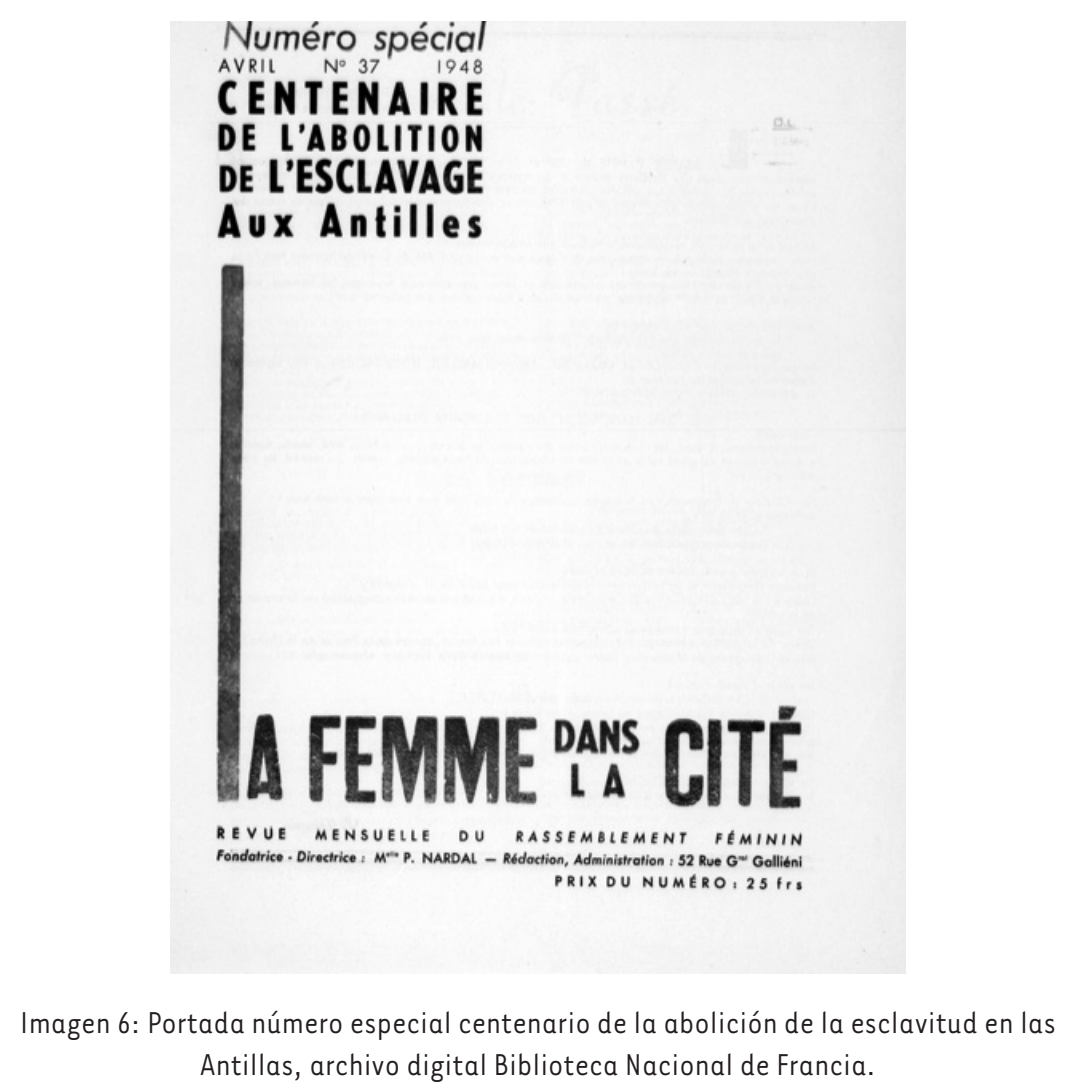

Mary Louise Pratt sostiene en sus investigaciones que, hasta 1945, el internacionalismo primaba entre las intelectuales latinoamericanas, quienes 
privilegiaron un pensamiento hemisférico más que nacional (55). ¿En qué medida el impreso martiniqueńo de Nardal desarrolla una actualización de ese internacionalismo? ¿En qué dimensiones su proyecto expresa la reconfiguración de ese escenario y utiliza los recursos disponibles para la abstracción de dos significantes transversales en su revista (como la mujer y la ciudad)? La mayor certeza al respecto es que en el conjunto de lo que la misma Pratt reconoce como "prácticas de mediación transcultural" (traducción, edición, recopilación y selección para antologías) (55), Nardal posee una amplia trayectoria en el oficio desde sus estudios formales en París. Nardal es una editora que actúa con pleno conocimiento de su campo, lo que le permite imprimir una racionalidad en su revista antillana que logra anudar, por un lado, la filiación ideológica y, por otro, las aperturas estéticas, las posibles filiaciones de esa ciudadanía en formación.

Ahora, si La Femme dans la Citélogró contribuir al traslado transregional de una cultura impresa transculturadora, esto fue posible porque la producción de ese objeto se desarrolló en el marco de un programa de ideologización feminista-cristiana que consideró el concepto de ciudadanía como una página en blanco posible de dotar de contenido e imaginar de un modo radicalmente diferente. El fin de la Segunda Guerra aparece íntegramente en estas páginas como la oportunidad histórica de un nuevo orden mundial $\mathrm{y}$ de un nuevo pacto entre vida, valores y tradiciones ${ }^{21}$.

\section{La Sección de variedades “Dans la Cité"}

Esa página en blanco de la ciudadanía se materializa, en gran medida, en la sección de variedades "Dans la cité". Si el editorial de cada número funciona como espacio de anclaje de la orientación valórica y el diálogo con la tradición, la sección de variedades es el lugar del ensayo, el montaje y la imaginación. Desde el siglo XIX, la sección de variedades comenzó

$21 \quad$ Es importante destacar la insistencia del periódico en la figura de la madre, y las ellas como lectoras-interlocutoras, a pesar de que Nardal nunca fue madre. 
a utilizarse y a cobrar gran popularidad por ser un recurso efectivo para dialogar instantáneamente con la nueva lectoría y fidelizar nuevos públicos lectores (Goldgel 97). Temas, notas, anuncios, curiosidades, sin un vínculo aparente arman un conjunto textual del que puede abstraerse tanto la contingencia como la sensibilidad del período. La ciudad montada en esta sección a ratos se hermana con las grandes metrópolis e inscribe nuevas preocupaciones para instalar referentes e imaginarios que integran un proyecto de modernización.

La sección muestra que, mediante el montaje de notas y noticias, incluso inconexas entre sí, construye su propio horizonte de expectativas para sus nuevas lectoras. Mes a mes, apuesta a trazar un sentido común de intereses. Es así como en la sección de enero de 1948, n. ${ }^{\circ} 33$, en la misma plana se critica el intervencionismo económico y el abuso de ciertas empresas extranjeras, el retraso en los pagos del hospital civil, seguidas de novedades en la prensa, obras sociales, un concurso de vals martiniqueńo organizado por Le Rassemblement Féminin, la inauguración de la Radio Martinique, una conferencia sobre las civilizaciones precolombinas, una exposición de pintura sobre paisajes de la isla, el anuncio de la aplicación de un seguro de vejez y los efectos del crudo invierno en Estados Unidos para las mujeres (ver imagen 7).

Dos números después, aparece en la misma sección un relato del estreno en Martinica, gracias al mecenazgo de la autoridades administrativas, de la película L'Enfer des Anges sobre la dramática realidad de los niños abandonados, el saludo celebratorio a André Midas por su nombramiento como corresponsal de la Comisión Caribe, una nota sobre la seguridad social de los ancianos y las condiciones en las que viven en Copenhague comparativamente a lo que ocurre en Martinica, la alta confluencia y calidad de una conferencia literaria a cargo del dominicano R. P. Chéry luego de mucho tiempo en que Martinica no tuvo actividades de este tipo.

Pero también la sección se ajusta a la contingencia, en el número conmemorativo del aniversario de la abolición de la esclavitud en las Antillas se renombra como "Dans le passé" e incluye leyendas, poemas y refranes en torno al número temático. Asimismo, en el número de 
julio de 1951, último año de publicación de la revista, se celebra el aniversario de la Unión Femenina Cívica y Social de París y no incluye la sección "Dans la cité". Más voluminosa en esta edición, a la vez que le rinde pleitesía a su par parisina, la revista entrega más espacio a la exposición de los conflictos interraciales antillanos con artículos que rozan la polémica y se enfocan en la denuncia de la segregación racial en la isla (por ejemplo, los artículos “¿Discriminación racial?” o "Racismo”), y aparecen intercalados con numerosas páginas dedicadas a eventos de las artes y la cultura ocurridos en las Antillas y París.

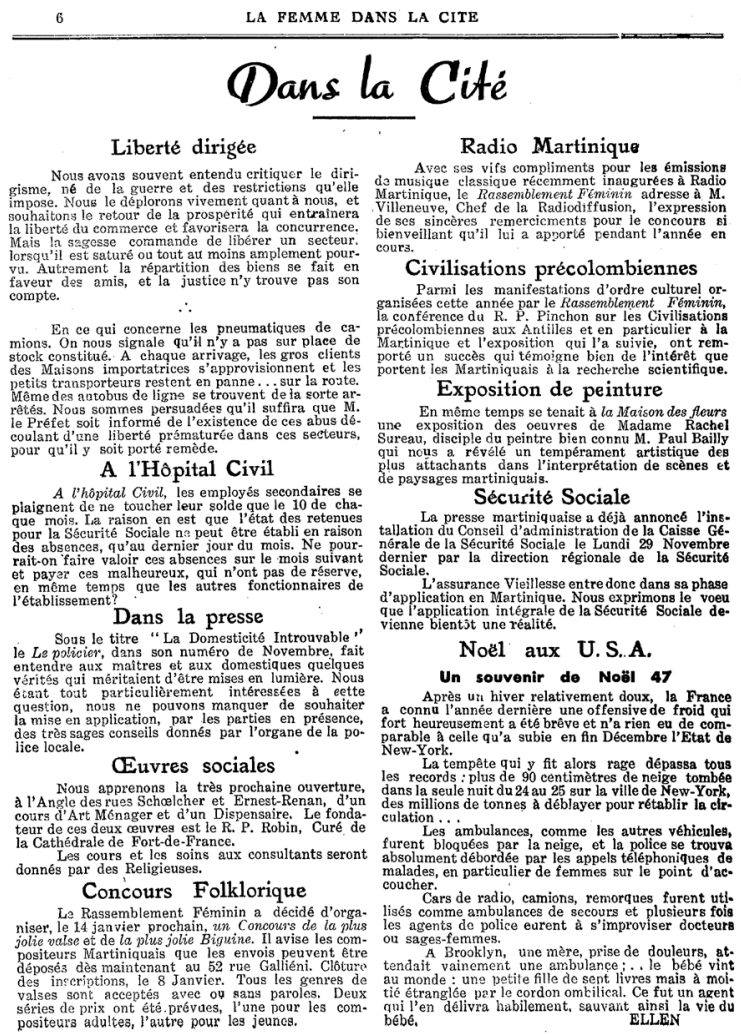

Imagen 7. La Femme dans la Cité, n. ${ }^{\circ} 33$, enero de 1948, archivo digital Biblioteca Nacional de Francia. 
La amplitud de temas y las escalas de referencias, locales y globales, que la revista presenta nos lleva a interrogar qué sujetos prefigura este impreso. Ese interrogante resuena en uno de los debates medulares de cultura material sistematizados por Miller (8-9), a saber, en qué momento se produce una distinción entre el objeto y el sujeto, cómo la relación entre sujeto-objeto constituye más bien un continuo de objetivaciones en que la materialidad prefigura al sujeto. Todo impreso prefigura un/unos/unas sujeto/as, y encarna diferentes objetivaciones posibles, podríamos pensar desde Miller. En cada número de La Femme dans la Cité, la convergencia de los editoriales proselitistas de Nardal con las secciones interiores y la protagónica "Dans la cité" muestran objetivaciones posibles en un contexto en que el mismo concepto de ciudadanía es un campo abierto. La vocación modernizadora de los impresos de Nardal, extiende sus marcos a una suerte de ciudadanía utópica: Fort-de-France deja de tener un referente único, se muestra como un significante. Porque, ¿cuál es ciudad que aparece en esta revista? ¿En qué ciudad ocurren las novedades y noticias de interés para la nueva ciudadana? Puede ser Fort-de-France, París, Nueva York indistintamente o todas juntas, si el montaje permite dibujar un bosquejo de ese horizonte por venir en que la ciudadanía podría ser cosmopolita y transfronteriza.

Es así como esta revista nos permite reconocer una forma de transculturación impresa: el modo en que una publicación antillana, que sigue los modos globales de producción de impresos, posee la capacidad de negociar y transformar los horizontes posibles de una ciudadanía en construcción. El peso de la cultura impresa periférica está en la capacidad de proyectar y transformar los modos en que se entiende la democracia en los inicios de la Cuarta República francesa, en una capacidad bidireccional de, por una parte, educar/formar localmente, y, por otra, proyectar o directamente imaginar esta inédita ciudadanía en los bordes globales de lo nuevo. 


\section{Conclusiones}

La Femme dans la Cité contribuyó a la construcción de un contrapúblico inédito en Fort-de-France. Un contrapúblico que posteriormente transformó el concepto de ciudadanía y de democracia en el Imperio francés por acción de las mujeres negras. Esa batalla ideológico-política desarrollada por diferentes mujeres negras en diversos puntos de la extensión colonial francesa que Joseph-Gabriel estudia, implicó una producción de impresos entre los que la revista de Nardal cumple un rol central en las Antillas. Nardal produce objetos impresos, al modo que aprendió en sus años en la Francia hexagonal, que transforman, en su producción, circulación y consumo, los marcos de la ciudadanía posible en ese contexto. Es decir, hubo transculturación en esos impresos, y esos impresos a su vez modulan continuas transculturaciones que transforman los horizontes de sus propias condiciones de posibilidad.

Este artículo aborda la productividad del concepto de transculturación (Ortiz) para la investigación de los impresos, y su rol específico en la construcción de contrapúblicos subalternos (Fraser). En este caso, el contrapúblico que se forma con el internacionalismo negro y sus disputas específicas en el período de entreguerras y también el contrapúblico construido por mujeres en las Antillas francesas una vez aprobado el voto femenino en 1944. El nuevo pacto colonial que incorpora a las mujeres antillanas con un rol político implica un horizonte cultural inédito. Desde La Femme dans la Cité se tensionan los términos de esa asimilación particularmente en cuanto al rol de las mujeres en la nueva ciudadanía, su lugar en la transformación de las relaciones interraciales y en los conflictos que perviven entre la Francia hexagonal y la Francia antillana una vez oficializada la departamentalización.

La Femme dans la Cité, a la vez que participa de un contrapúblico en formación, escribe las primeras líneas del lugar que tendrán las mujeres antillanas en la Cuarta República francesa y, desde allí, transcultura el concepto de ciudadanía de su momento. Este artículo, por tanto, 
muestra cómo los objetos impresos, y en particular esta revista, pueden ser inscritos en una lectura más amplia sobre la transculturación impresa y la formación de contrapúblicos en las Antillas francesas. 


\section{Bibliografía}

Appadurai, Arjun. La vida social de las cosas: perspectiva cultural de las mercancías. México D. F.: Grijalbo/CNCA, 1991.

Bascunán, Patricio. "La tipografía moderna entre la ideología y la utilidad. Una revisión de las propuestas de Jan Tschichold y Otl Aicher”. Revista Chilena de Diseño: creación y pensamiento, vol. 1, n. ${ }^{\circ} 1,2016$, pp. 95-103.

Beigel, Fernanda. "Las revistas culturales como documentos de la historia latinoamericana”. Revista Utopia y Praxis Latinoamericana, vol. 8, n. ${ }^{\circ} 20$, 2003, pp. 105-15.

Boittin, Jennifer Anne. Colonial Metropolis. The Urban Grounds of Anti-Imperialism and Feminism in Interwar Paris. Nebraska: University of Nebraska Press, 2015.

Bollenot, Vincent. “'Ne visitez pas l'exposition coloniale!'. La champagne contre l'exposition coloniale internationale de 1931, un moment anti-impérialiste". French Colonial History, vol. 18, 2019, pp. 69-100

_. À bas l'exposition coloniale! Acteurs, réseaux, mobilisations (France, 1931). Tesis de magíster, Escuela Normal Superior de Lyon, 2014.

Boni, Tanella. "Femmes en Négritude: Paulette Nardal et Suzanne Césaire". Rue Descartes, n. ${ }^{\circ} 83,2014$, pp. 62-76.

Bourdieu, Pierre. La distinción. Criterio y bases sociales del gusto, Buenos Aires, Taurus, 1998.

Bruneel, Emmanuelle y Tauana Olivia Gomes Silva. "Paroles de femmes noires. Circulations médiatiques et enjeux politiques". La Découverte, n. ${ }^{\circ} 201$, 2017, pp. 59-85.

d'Andurain, Julie. "Entre velléité et opiniâtreté: La création du Ministère des Colonies en France (1858-1894)”. French Colony Research, vol. 14, 2013, pp. 33-54.

Dalleo, Raphael. Caribbean Literature and the Public Sphere. From the Plantation to the Postcolonial. Virginia: University of Virginia Press, 2011

Darnton, Robert. “¿Qué es la historia del libro?”. Prismas, Revista Historia Intelectual, n. ${ }^{\circ} 12,2008$, pp. 135-55.

_. The Business of Enlightenment. A Publishing History of the Encyclopédie, 1775- 
1800. Cambridge y Londres: The Belknap Press of Harvard UP, 1979.

Demougin, Laure. "Paulette Nardal ou une négritude par la presse". Journée d'études: le statut des périodiques francophones dans le monde (1880-1980). Le Mans: Universidad de Le Mans, 2019.

Depestre, René. Buenos días y adiós a la negritud. La Habana: Casa de las Américas, 1986.

Douglas, Mary y Baron Isherwood. El mundo de los bienes: hacia una antropología del consumo. México D. F.: Grijalbo, 1990.

Edwards, Brendt Hayes. "Feminism and L'internationalisme Noir: Paulette Nardal". The Practice of Diaspora. Literature, Translation, And The Rise Of Black Internationalism. Harvard: Harvard UP, 2003, pp. 119-89.

Fraser, Nancy. "Pensando de nuevo la esfera pública. Una contribución a la crítica de las democracias existentes". Iustitia interrupta. Reflexiones criticas desde la posición "postsocialista". Bogotá: Siglo del Hombre Editores, 1998, pp. 95133.

Gianoncelli, Eve. La Pensé Conquiste. Contribution à une Histoire Intellectuelle Transnationale des Femmes et du Genre au XXe Siècle. Tesis doctoral en Ciencias Políticas, Universidad de París 8, 2016.

Gilroy, Paul. Atlántico negro: modernidad y doble conciencia. Madrid: Akal, 2014.

Goldgel, Víctor. Cuando lo nuevo conquistó América. Prensa, moda y literatura en el siglo XIX. La Habana: Casa de las Américas, 2016.

Grollemund, Philippe. Fiertés de femme noire. Entretiens/Mémoires de Paulette Nardal, París: L'Harmattan, 2019.

Guide des colonies: Martinique, Guadeloupe, Guyane française. Paris: Société D’éditions Géographiques, Maritimes, et Coloniales, 1931.

Joseph-Gabriel, Annette K. Reimagining Liberation: How Black Women Transformed Citizenship in the French Empire. Illinois: University of Illinois Press, 2019.

La Dépêche Africaine. Archivo digital Biblioteca Nacional de Francia.

La Femme dans la Cité: Revue Mensuelle du Rassemblement Féminin, 1945-1951. Archivo digital Biblioteca Nacional de Francia.

La Revue du Monde Noire. The review of the black word. Collection complète, n. ${ }^{\circ}$ 1-6. Paris: Jean-Michel Place, 1992. 
Lao-Montes, Agustín. "Cartografías del campo político afrodescendiente en América Latina”. Universitas Humanistica, n. ${ }^{0}$ 68, 2009, pp. 207-46.

Les Annales Coloniales: Revue Mensuelle Illustrée, n.o 3, 1935, Archivo digital Biblioteca Nacional de Francia.

Miller, Daniel, ed. “Introduction”. Materiality. Durham: Duke UP, 2005.

Musil Church, Emily. "In Search of Seven Sisters: A Biography of the Nardal Sisters of Martinique". Callaloo, vol. 36, n. ${ }^{\circ}$ 2, 2013, pp. 375-90.

Ortiz, Fernando. Contrapunteo cubano del tabaco y el azúcar. Caracas: Biblioteca Ayacucho, 1978.

Palmiste, Clara. "Le vote féminin et la transformation des colonies françaises d'Amérique en départements en 1946". Nuevo Mundo Mundos Nuevos, Coloquios, 5 junio 2014.

Pita González, Alexandra. "Las revistas culturales como soportes materiales, prácticas sociales y espacios de sociabilidad”. Almacenes de un tiempo en fuga: revistas culturales en la modernidad hispánica. Editado por Hanno Ehrlicher y Nanette Ribler-Pipka. Berlín: ShakerVerlag, 2014, pp. 227-45.

Pratt, Mary Louise. "Las mujeres y el imaginario nacional en el siglo XIX". Revista de Crítica Literaria Latinoamericana, n. ${ }^{\circ}$ 38, 1993, pp. 51-62.

Sharpley-Whiting, T. Denean. Beyond Negritude: Essays from Woman in the City. Nueva York: State University of New York Press, 2009.

_. $\quad$ "Femme negritude. Jane Nardal, La Depeche africaine, anthe Francophone New Negro". Souls, vol. 2, n. ${ }^{\circ} 4$, 2000, pp. 8-17.

_. $\quad$ Negritude Women. Minnesota: University of Minnesota Press, 2002.

Schwartz, Jorge. Las vanguardias latinoamericanas. Textos programáticos y criticos, México: Fondo de Cultura Económica, 2002.

Toledo, Magdalena Sophia. "Surrealismo negro, anticolonialismo y la identidad martinicana”. Revista Aisthesis, n. ${ }^{\circ}$ 64, 2018, pp. 119-37.

Viu, Antonia. Materialidades de lo impreso revistas latinoamericanas 1910-1950, Santiago: Metales Pesados, 2019.

_. “'Como rebrote de una misma arborescencia'. Recortes, ciencia y saberes en Ultra Cultura Contemporánea (La Habana, 1936-1947)". Universum, vol. 36, n. ${ }^{\circ}$ 1, 2021, pp. 89-107. 